\title{
Finite Elemental Analysis of Pull and Release Trolley for Conducting Vehicle Crash Tests
}

\author{
Dhananjay S. Bhalerao ${ }^{\# 1}$, Sandip A. Kale ${ }^{\# 2}$, Kumar D. Sapate ${ }^{\# 3}$, Abhay V. Mannikar ${ }^{* 4}$ \\ "Trinity College of Engineering and Research, Pune, India \\ 1dhananjaysbhalerao@gmail.com \\ 2sakale2050@gmail.com \\ ${ }^{3}$ kdsapate09@gmail.com \\ *The Automotive Research Association of India, Pune, India \\ ${ }^{4}$ mannikar.psl@araiindia.com
}

\begin{abstract}
The full scale vehicle crash tests or component level sled tests are carried out in the laboratory to ensure minimum occupant safety. These tests are conducted according to internationally adopted regulations. The test configurations are full frontal, offset frontal, side and rear impact. These tests are destructive and involve significant cost. Pros and cons of different methods for conducting crash test are studied. It is revealed that for the assessment of the possible occupant injuries, it is necessary to conduct the crash tests in most accurate way. Using rail track guide and trolley system, it is possible to conduct the crash tests in accurate way. In a typical crash test, a vehicle to be tested is first set at the launch position. The vehicle pulled towards barrier along a rail track is connected to a pull and release trolley. This trolley is typically driven by AC drive system through a wire rope. The test vehicle and wire rope are required to be released from trolley before the impact. For a crash test, the important parameters are the test speed, impact plane, linear motion and release of the vehicle. These parameters are controlled with the help of the trolley. This trolley is also used for sled tests in addition to the crash tests. At the time of designing the trolley, several test methods and different configurations are discussed. The parts are modeled considering function, manufacturing feasibility and user access. From the perspective of function and operation, the forces experienced by the trolley are dynamic in nature. Geometry of parts used in trolley is complex. Hence finite elemental analysis technique is used over the analytical and experimental technique of analysis. LS-DYNA used in case of engineering problems that include non-linear finite element analyses, such as automotive crashworthiness. The final analysis is done with the help of Hypermesh V12 and LS-DYNA V971 R6 software. The results obtained from the analysis are found satisfactory.
\end{abstract}

Keywords—crash testing; FEA; test trolley; vehicle safety

\section{INTRODUCTION}

Automobiles have become the inherent need of society [1]. As per European Automobile Manufacturers Association (ACEA) report 2013, passenger car sales rose to 70 million, i.e. $75 \%$ rise compared to figures in 90's [2]. The flip side of the boost of vehicle sale is increase in road accidents and fatalities [3] [4]. The World Health Organisation (WHO) report [5] published in 2013 shows that there are 1.24 million deaths on the world's road in 2010. To cater this problem, vehicle manufacturers started producing safer vehicles. This activity has been assisted by many governments by enforcing the minimum crash requirements for the vehicles and promoting the technologies that makes the vehicle safer. The safety of occupants is nowadays ensured with the help of one or a combination of different types of safety devices fitted in the vehicles [6] such as collapsible steering columns, dual stage airbags, curtain bags, seat-belts and head-restraints, etc. In the event of front, side or rear impact, occupant is restrained by these safety systems fitted in the vehicle. In event of accident the risk of injury of the occupant is more especially when structural deformation occurs in the area of occupant compartment [7]. This impact environment reproduces in the laboratory for conducting the crash test. These tests must be conducted accurately and in a careful manner since tests are destructive and involves significant testing cost. This test setup consists of a rail track, sling of wire rope, pull and release trolley, wire rope, AC drive and a barrier. The test vehicle is moving along the rail track is connected to the pull and release trolley by a sling with hook. The trolley is driven by an AC drive through a wire rope. During the test, the trolley pulls the test vehicle and offers required test speed to the vehicle. Further, the sling and wire rope are released from the trolley before the test vehicle strikes to the barrier. Once the trolley is free to decelerate on the rail track, it strikes to a shock absorber. Hence, it is necessary to carry out the impact analysis of the trolley. Analytical and experimental techniques to carry out impact analysis of the trolley are too complex and involve a lot of time, cost and complicated experimental setup. Compare to these techniques, computational analysis is suitable and used in this work. The results of computational analysis are presented in this paper. 


\section{CRASH TESTING}

Real world crashes are complex events for which one cannot estimate a typical crash scene to predict the combination of crashes [8]. In the early stage, when the crash testing is carried out, the frontal collision is considered for analysis in detail [9]. In addition to frontal impact test, other type of tests like, side impact, oblique impact, low speed rear impact, pole impact, rollover and car to car collision tests are also carried out in the laboratory. All these tests are mostly conducted by acceleration method. One of the methods is developed by an inventor Walter Cerny, shown in Figure 1, from Ford Motor Co. [10], uses an acceleration method, in which the vehicle is accelerated on a track by means of a driving arrangement before it strikes an obstacle. In this arrangement of crash test, data recording instrument is mounted on the follower vehicle guided behind the test vehicle. The follower vehicle applies the brakes before the test vehicle crashes against the obstacle. A measuring cable connection is provided between the vehicle and the follower vehicle, which has a length at least great enough to cover the distance between the vehicle in the crashed condition and the follower vehicle in the braked condition. It is not possible to conduct all required crash test using this arrangement of crash testing and this is a huge draw back.

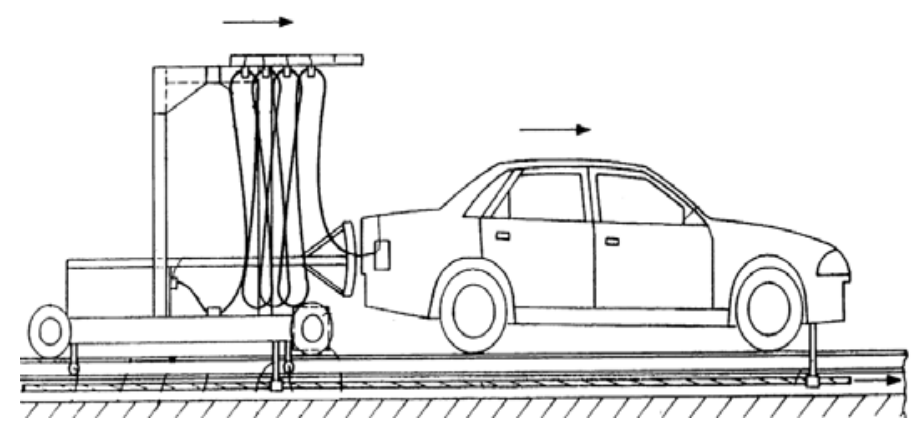

Figure. 1. Crash test method proposed by Walter Cerny [10]

Another method uses the wireless guiding method [11] known as electronically controlled vehicles (ECV). It can simulate almost any type of collision. This method also uses acceleration of the vehicle. Two wires acting as transmitter are embedded in the tar road cum track on which vehicle runs. The vehicle is guided through the receiver fitted on it. This method has some disadvantages. First, lots of vehicle trials require to achieve the tunning of vehicle with ECV system. Hence, it beomces a time consuming activity and also the safety of driver and co-driver sat in the vehicle is not considered here. Second, it is not possible to conduct all types of crash tests using this system.

The schematic of developed crash test setup is shown in Figure 2. This setup consists of a rail track, sling of wire rope, pull and release trolley, an endless loop of wire rope, computer controlled close loop AC drive system, drive pulley, idler pulley, turnaround pulley and a barrier. The test vehicle is pulled by a trolley along the rail track at required test speed. The trolley speed is controlled by the computerised AC drive. The trolley is connected to test vehicle and AC drive by sling and close loop wire rope respectively. Before impact, it is essential to release the vehicle and AC drive from the trolley. Hence, the trolley is named as pull and release trolley. 

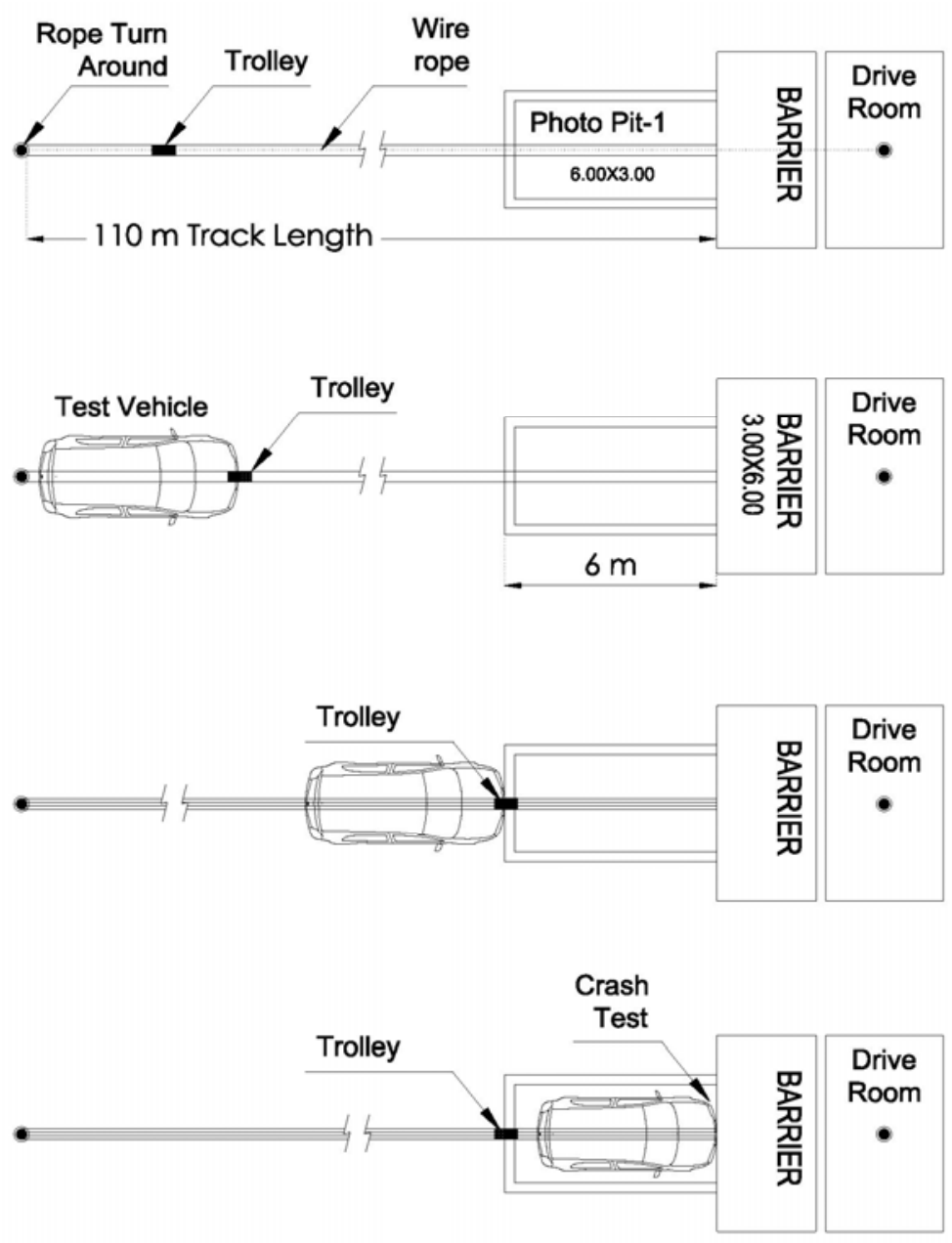

Figure. 2. Crash test setup

\section{Design of Pull and Release Trolley}

Trolley is designed to accommodate the rail track. The rail track is embedded for its entire length in the concrete up to its top plates as shown in Figure 3.

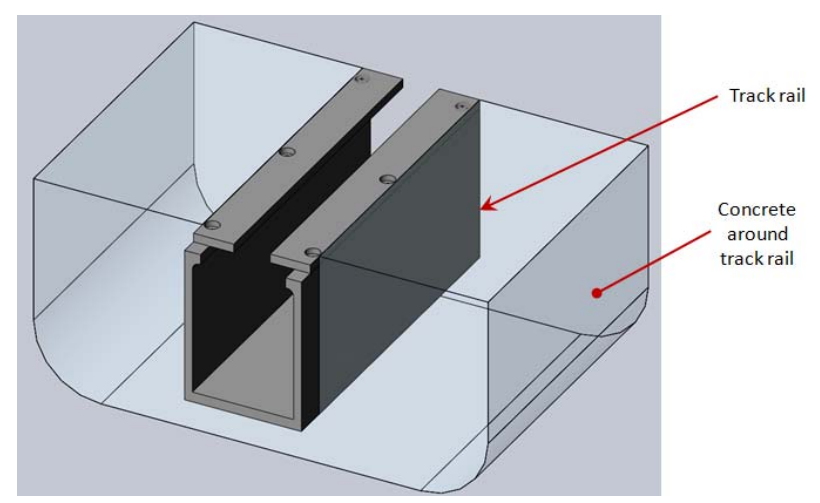

Figure. 3. Rails embedded in concrete

The overall dimensions and shape of trolley are designed considering the working area available for the operator, number of wheels required, accommodation of shock absorber, location of wire rope, types of vehicle to be tested and obstruction to the other parts.

The schematic of vehicle being pulled alsong a rail track using the pull and release trolley is shown in Figure 4. After sevral itrations of design options the final shape obtained for different parts is complex and also the material used for these parts is of different type for many parts. In regards to strenth assessment of pull and release trolley, with the help of analytical technique, it is difficult to compute the value of stresses developed in the trolley parts. As like analytical technique, the experimental technique is also not suitable because the data 
recording process would have been very complecated, time consuming and costlier. In addition to this, the possibilities of loss of data or damage to data recoding instrument are imminent. Hence the finite elemental analysis technique is considered for computation of stresses induced in the trolley.

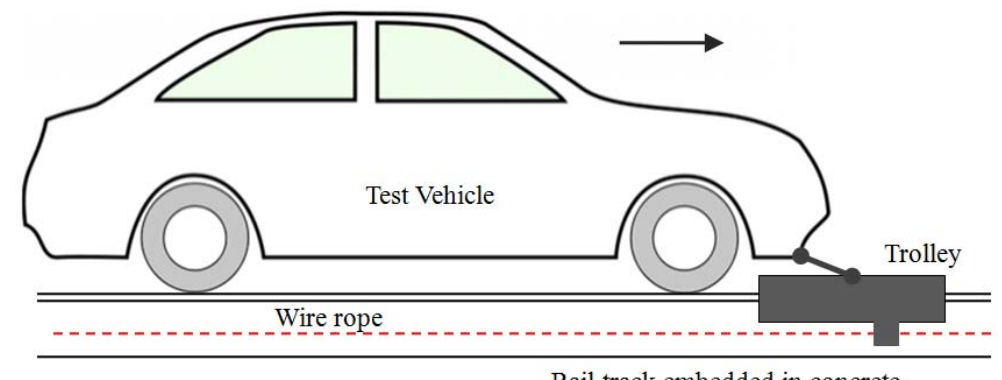

Figure. 4. Pull and release trolley

The finite element simulation help designers understand how components interact and how the failure mode and mechanism is developed under the impact loading [12]. For the finite elemental analysis following conditions are considered, the shock absorber have unidirectional displacement of $254 \mathrm{~mm}$, time required for the complete displacement is taken $50 \mathrm{~ms}$. The kinetic energy dissipation on the timescale is shown in Figure 5 and displacement decay is shown in Figure 6.

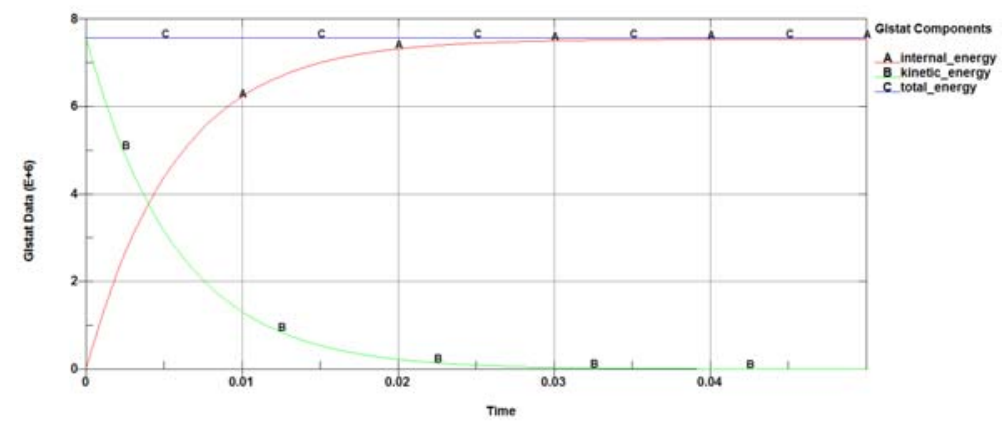

Figure. 5. Kinetic energy dissipation

The Altair Hypermesh [13] is a finite element pre-processor. HyperMesh enables to receive high quality meshes with maximum accuracy in the shortest time possible. Meshing algorithms for shell and solid elements provide full level of control. HyperMesh offers the variety of solid meshing capabilities, including domain. For the trolley block, the tetrahedron mesh is used. The numbers of node and elements are 4892 and 17092 respectively. Figure 7 meshing of the trolley.

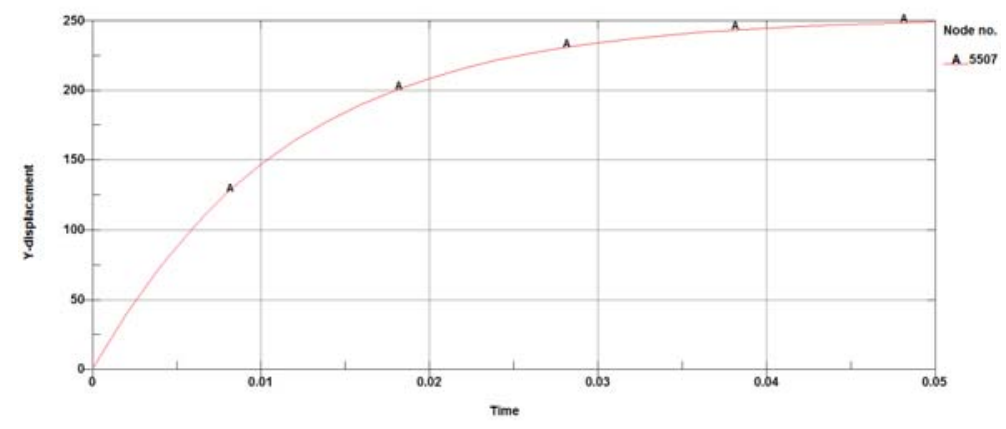

Figure. 6. Displacement of shock absorber 


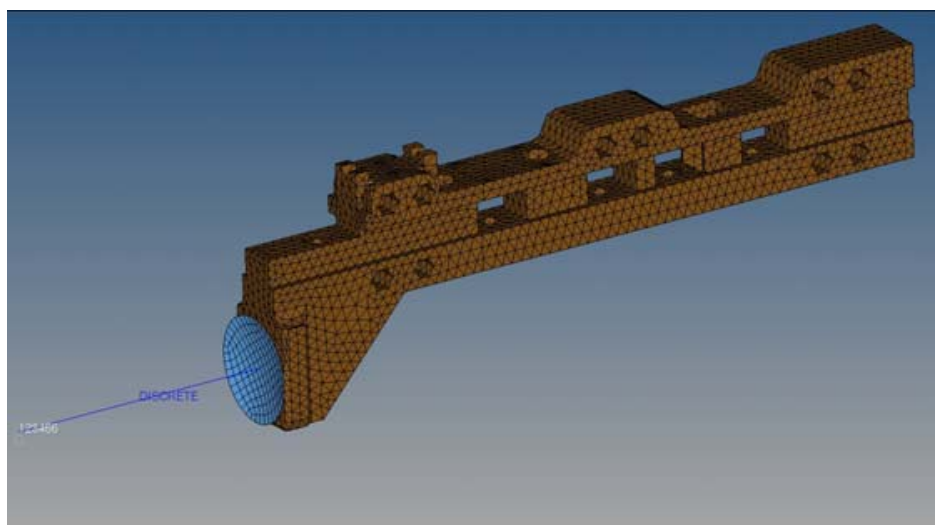

Figure. 7. Meshing of trolley

The material selection of trolley block is crucial from the kineic energy point of view. Because the kinetic energy is directly proportional to the weight. In order to constrain the energy, the properties of the material selected for the trolley block is given in table I.

TABle i. Material Properties

\begin{tabular}{|l|l|}
\hline Material & Aluminum alloy \\
\hline Density & $2795 \mathrm{~kg} / \mathrm{m}^{3}$ \\
\hline Ultimate tensile strength & $427 \mathrm{Mpa}$ \\
\hline Yield tensile strength & $290 \mathrm{Mpa}$ \\
\hline Poisson's ratio & 0.33 \\
\hline
\end{tabular}

LS-DYNA [14] is a highly advanced general purpose nonlinear finite element program that is capable of simulating complex real world problems. The post-processing is done in LS-DYNA. This distributed and shared memory solver provides very short turnaround time. It can investigate phenomena involving large deformations, sophisticated material models and complex contact conditions for structural dynamics problems. Carrying out investigations with the aid of LS-DYNA supports the design of robust products with superior performance. For many automotive companies, LS-DYNA is an indispensable tool for understanding the mechanisms associated with the deformation of complex systems e. g. vehicle structures in a crash. As a rule, far more crash scenarios can be investigated numerically than physical tests can be performed. A further benefit is that, the time to market can be reduced significantly by applying LS-DYNA during product development. The analysis shows the maximum von mises stress is within acceptable limit and it is present just momentarily. The report of analysis is given in Figure 8. The computational dynamic strength analysis of pull and release trolley shows that designed system is safe in critical crash testing setup. From these result it is concluded that the developed new system has ability to withstand complex forces generated during test.

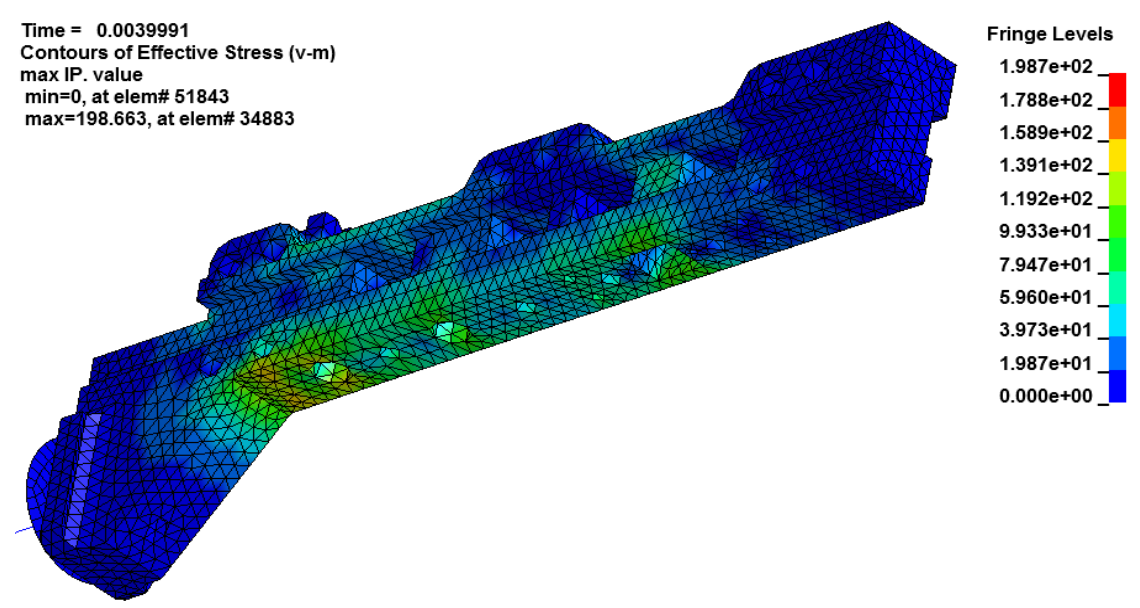

Figure. 8. Analysis report for trolley 


\section{CONCLUSION}

The simulation of trolley shows that arrangement of all designed parts found satisfactory. The computational dynamic strength analysis of pull and release trolley shows that designed system is safe in critical crash testing setup. From these result it is concluded that the developed new system has ability to withstand complex forces generated during test. The results of impact analysis shows the von mises stress is within the safe limits.

\section{REFERENCES}

[1] M. Emberger, Driving Future Vehicles, Taylor \& Francis, 2003, pp. 15.

[2] Quynh-NhuHuyNH, The Automotive Industry Pocket Guide, 2013, pp. 39.

[3] D. Mohan, "Road Accidents in India” IATSS Research, vol. 33, issue 1, 2009, pp. 75-79.

[4] G. Kondala Rao, “Road Traffic Safety Management in India-Analysis-Exploring Solutions, ” IJAIEM, vol 2, Issue 12, 2013 , pp. 3.

[5] WHO 2013, Global Status Report on Road Safety 2013.WHO Library, pp. 15.

[6] S. J. Cloutier and D. H. Linke, Automobile Safety Technology-An interactive Qualifying Project, 2011, unpublished.

[7] IIHS, Guidelines for Rating Structural Performance December IIHS Publication, 2011, pp. 3.

[8] G. Mastinu and M. Ploechl, Road and Off-Road Vehicle System Dynamics Handbook, CRC Press, 2014 , pp. 1621.

[9] U. Seiffert and L. Wech, Automotive Safety Handbook, 2nd ed. SAE Publication, 2003, pp. 127.

[10] W. Cerny, Apparatus for carrying out a crash test on a motor vehicle, 1997, US patent US5635624A.

[11] TÜV SÜD Automotive GmbH, Germany, http://www.bayern-innovativ.de/2cc36d40-24a1-b116-067b-893c42f31da3

[12] V. B. Bhandari, Design of Machine Elements, Tata McGraw-Hill, 2008

[13] W. Liu and H Li, "Impact Analysis of a cellular Phone" 4th ASA \& $\mu$ ETA International Conference.

[14] Altair Hyperworks, www.altairhyperworks.in

[15] J. O. Hallquist, LS-DYNA Theoretical Manual, Livemore Software Technology Corporation, 2006. 